\title{
High-Specific Impulse Hall Thrusters, Part 1: Influence of Current Density and Magnetic Field
}

\author{
Richard R. Hofer* \\ QSS Group, Inc., Cleveland, Ohio 44135 \\ Robert S. Jankovsky ${ }^{\dagger}$ \\ NASA John H. Glenn Research Center at Lewis Field, Cleveland, Ohio 44135 \\ and \\ Alec D. Gallimore \\ University of Michigan, Ann Arbor, Michigan 48109
}

\begin{abstract}
A laboratory-model Hall thruster with a magnetic circuit designed for high-specific impulse (2000-3000 s) was evaluated to determine how current density and magnetic field affect thruster operation. Results have shown for the first time that a minimum current density and optimum magnetic field shape exist at which efficiency will monotonically increase with specific impulse. At the nominal mass flow rate of $10 \mathrm{mg} / \mathrm{s}$ and between discharge voltages of 300 and $1000 \mathrm{~V}$, total specific impulse and total efficiency ranged from 1600 to $3400 \mathrm{~s}$ and 51 to $61 \%$, respectively. Comparison with a similar thruster showed how efficiency can be optimized for specific impulse by varying the shape of the magnetic field. Plume divergence decreased from a maximum of $48 \mathrm{deg}$ at $400 \mathrm{~V}$ to a minimum of $35 \mathrm{deg}$ at $1000 \mathrm{~V}$, but increased between 300 and $400 \mathrm{~V}$ as the likely result of a large increase in discharge current oscillations. The breathing-mode frequency continuously increased with voltage, from $14.5 \mathrm{kHz}$ at $300 \mathrm{~V}$ to $22 \mathrm{kHz}$ at $1000 \mathrm{~V}$, in contrast to other Hall thrusters where a sharp decrease of the breathing-mode frequency was found to coincide with increasing electron current and decreasing efficiency. These findings suggest that efficient, high-specific impulse operation was enabled through the regulation of the electron current with the applied magnetic field.
\end{abstract}

\section{Nomenclature}

\begin{tabular}{|c|c|}
\hline$B_{r, \max }$ & $\begin{array}{l}=\text { maximum radial magnetic field on discharge } \\
\text { chamber centerline }\end{array}$ \\
\hline$B_{0}$ & $=$ magnetic field normalization constant \\
\hline$g$ & $=$ acceleration of gravity, $9.80665 \mathrm{~m} / \mathrm{s}^{2}$ \\
\hline$\stackrel{O}{I}_{d}$ & $=$ discharge current \\
\hline$I_{\mathrm{sp}, a}$ & $=$ anode specific impulse \\
\hline$I_{\mathrm{sp}, t}$ & $=$ total specific impulse \\
\hline$j$ & $=$ ion current density \\
\hline$\dot{m}_{a}$ & $=$ anode mass flow rate \\
\hline$\dot{m}_{c}$ & cathode mass flow rate \\
\hline$\dot{m}_{t}$ & $=$ total mass flow rate, $\dot{m}_{a}+\dot{m}_{c}$ \\
\hline$P_{d}$ & $=$ discharge power, $V_{d} I_{d}$ \\
\hline$P_{\text {mag }}$ & $=$ electromagnet coil power \\
\hline$P_{t}$ & $=$ total input power, $P_{d}+P_{\mathrm{mag}}$ \\
\hline$T$ & $=$ thrust \\
\hline$V_{d}$ & $=$ discharge voltage \\
\hline $\bar{\beta}_{95}$ & average $95 \%$ plume divergence half-angle \\
\hline$\eta_{a}$ & anode efficiency \\
\hline$\eta_{c}$ & $=$ cathode efficiency, $\dot{m}_{a} / \dot{m}_{t}$ \\
\hline$\eta_{\text {mag }}$ & $=$ electromagnet coil efficiency, $P_{d} / P_{t}$ \\
\hline
\end{tabular}

Received 4 February 2005; revision received 20 December 2005; accepted for publication 3 January 2006. This material is declared a work of the U.S. Government and is not subject to copyright protection in the United States. Copies of this paper may be made for personal or internal use, on condition that the copier pay the $\$ 10.00$ per-copy fee to the Copyright Clearance Center, Inc., 222 Rosewood Drive, Danvers, MA 01923; include the code 0748-4658/06 \$10.00 in correspondence with the CCC.

* Research Engineer, Electric Propulsion Branch; currently Mamber of the Technical Staff, Mail Stop 125-109, Advanced Propulsion Technology Group, Propulsion and Materials Engineering Section, Jet Propulsion Laboratory, California Institute of Technology, 4800 Oak Grove Drive, Pasadena, CA 91109; richard.r.hofer@jpl.nasa.gov. Member AIAA.

${ }^{\dagger}$ Chief, Mail Stop 301-3, Electric Propulsion Branch, 21000 Brookpark Road; robert.s.jankovsky@ nasa.gov. Member AIAA.

† Professor, Department of Aerospace Engineering, Plasmadynamics and Electric Propulsion Laboratory, 3037 François-Xavier Bagnoud Building, 1320 Beal Avenue; alec.gallimore@umich.edu. Associate Fellow AIAA. $\begin{array}{ll}\eta_{t} & =\text { total efficiency } \\ \theta & =\text { azimuthal coordinate direction } \\ \nabla_{z} B_{r} & =\text { axial gradient of the centerline radial magnetic field }\end{array}$

\section{Introduction}

M OST often regarded as a 1600-s specific impulse technology, the Hall effect thruster has benefited from considerable theoretical and experimental research since the 1960s. ${ }^{1-3}$ Derived from research on magnetrons and other cross-field plasma sources, the first working devices were reported by Americans beginning in $1962,{ }^{4-8}$ but were first developed for spaceflight in the former Soviet Union. ${ }^{1-3}$ Hall thrusters first flew in space when a pair of thrusters was launched with the Soviet Meteor satellite in December 1971.9 Since that flight, over 140 Hall thrusters have flown on Earth-orbiting spacecraft, primarily for station keeping and orbit maintenance tasks. ${ }^{10}$ The first spacecraft to use Hall thrusters for primary propulsion outside of Earth's orbit was the ESA's SMART-1 spacecraft. ${ }^{11}$

Several trends in electric propulsion in general and Hall thruster technology in particular are requiring that the traditional notion of the Hall thruster as a 1600-s specific impulse device be reexamined. These include, at least, new materials and fabrication technologies, advanced computer simulations, the rapid rise in spacecraft power, and new missions requiring propulsion systems with larger operating envelopes, longer lifetimes, and greater efficiencies. ${ }^{12-16}$ These trends are requiring improvements to existing designs or expansion of the operating envelope to greater specific impulse and/or power. Expanding the operating envelope of Hall thruster technology has been the subject of several recent investigations. ${ }^{14-16}$ Separate studies have demonstrated power levels of $95 \mathrm{~kW}$ and specific impulses of $4000 \mathrm{~s}$ with xenon Hall thrusters. This paper discusses continuing efforts to develop high-efficiency, high-specific impulse xenon Hall thrusters.

\section{High-Specific Impulse Hall Thruster Development}

Western interest in Russian Hall thruster technology emerged in the 1990 s partly because the 1600 -s specific impulse characteristic of flight hardware fell between arcjets (less than $1000 \mathrm{~s}$ ) and gridded ion thrusters (greater than $3000 \mathrm{~s}$ ) (Refs. 1 and 13). After 
Russian Hall thrusters met western flight qualification standards in the mid-1990s, interest in expanding the specific impulse range developed, mostly toward $3000 \mathrm{~s}$, so that the Hall thruster could more fully bridge the 1000-3000 s specific impulse gap. These activities were motivated by studies indicating the mission benefits for Earth orbiting $^{13,17-21}$ and interplanetary ${ }^{21-25}$ spacecraft if Hall thrusters could operate efficiently at high-specific impulse (2000-3000 s). These benefits have included greater payloads, launch vehicle step downs, reduced trip times, or lower required power. Because the realization of these benefits depends on high-specific impulse Hall thrusters being available, a clear need exists to explore the development challenges of such technology enhancements.

In the late 1990s, the feasibility of operating modern, xenon Hall thrusters at high-specific impulse was investigated. Initially, three thrusters of differing design were developed by industry and performance tested. ${ }^{26-28}$ Specific impulse in excess of $4000 \mathrm{~s}$ was demonstrated at greater than $50 \%$ efficiency. However, it was found that efficiency maximized at less than 3000 -s specific impulse. The discharge voltage corresponding to maximum efficiency was between 500 and $800 \mathrm{~V}$ and depended on the current density and the thruster design. Analysis suggested that enhanced electron transport across the transverse magnetic field was the dominant mechanism limiting thruster efficiency. ${ }^{27,28}$ Understanding the causes of the efficiency maximum and developing thruster designs that could mitigate these effects, therefore, required additional study.

Follow-on efforts focused on the development and characterization of xenon Hall thrusters capable of both high-specific impulse and high-efficiency operation. ${ }^{29}$ The research resulted in the NASA$173 \mathrm{M}$ series of laboratory-model Hall thrusters. The designs of these thrusters were based on the hypothesis that the efficiency maximum observed with the commercially developed thrusters was actually a consequence of modern magnetic field designs that had been optimized for 1600 -s specific impulse. The new thrusters were, therefore, attempts to improve efficiency through the implementation of a magnetic circuit intended for high-specific impulse operation.

The role of the magnetic field in achieving efficient operation at high-specific impulse was first verified with the NASA-173M version 1 (v1) (Ref. 30). Experiments with the NASA-173Mv1 validated the magnetic circuit design by showing how tailoring the magnetic field for high-specific impulse operation enhanced efficiency. ${ }^{29,31}$ However, the efficiency-specific impulse characteristic of the NASA-173Mv1 showed a maximum at an intermediate value of specific impulse and was found to asymptote at highspecific impulse.

The NASA-173Mv1 experiments suggested several ways to refine the magnetic circuit so that a true high-specific impulse Hall thruster could be realized. The result was a new design, the NASA$173 \mathrm{M}$ version 2 (v2), which incorporated the design improvements suggested by its predecessor. The goal of the NASA-173Mv2 development was to obtain an efficiency that continuously increased with specific impulse.

To evaluate whether this goal was achieved, this paper presents results from a series of experiments exploring the operating characteristics of the NASA-173Mv2. In the experiments, performance was mapped while varying the discharge voltage from 300 to $1000 \mathrm{~V}$ at 5 and $10 \mathrm{mg} / \mathrm{s}$ and 300 to $600 \mathrm{~V}$ at $15 \mathrm{mg} / \mathrm{s}$. Ion current density and discharge current oscillation data were also collected at $10 \mathrm{mg} / \mathrm{s}$ between 300 and $1000 \mathrm{~V}$. In the sections that follow, the experimental apparatus are first discussed, followed by a presentation and discussion of the data. The primary result of the experiments shows that a monotonically increasing efficiency-specific impulse characteristic can be obtained so long as the thruster is operated above a minimum current density and with a magnetic field optimized for high-specific impulse.

\section{Experimental Apparatus}

\section{Hall Thruster}

Shown in Fig. 1, the laboratory-model NASA-173Mv2 is a singlestage, magnetic layer Hall thruster sized for a nominal discharge current of $10 \mathrm{~A}$ and discharge voltages of 500-800 V (Ref. 29). The boron nitride discharge chamber has an outer diameter of $173 \mathrm{~mm}$.

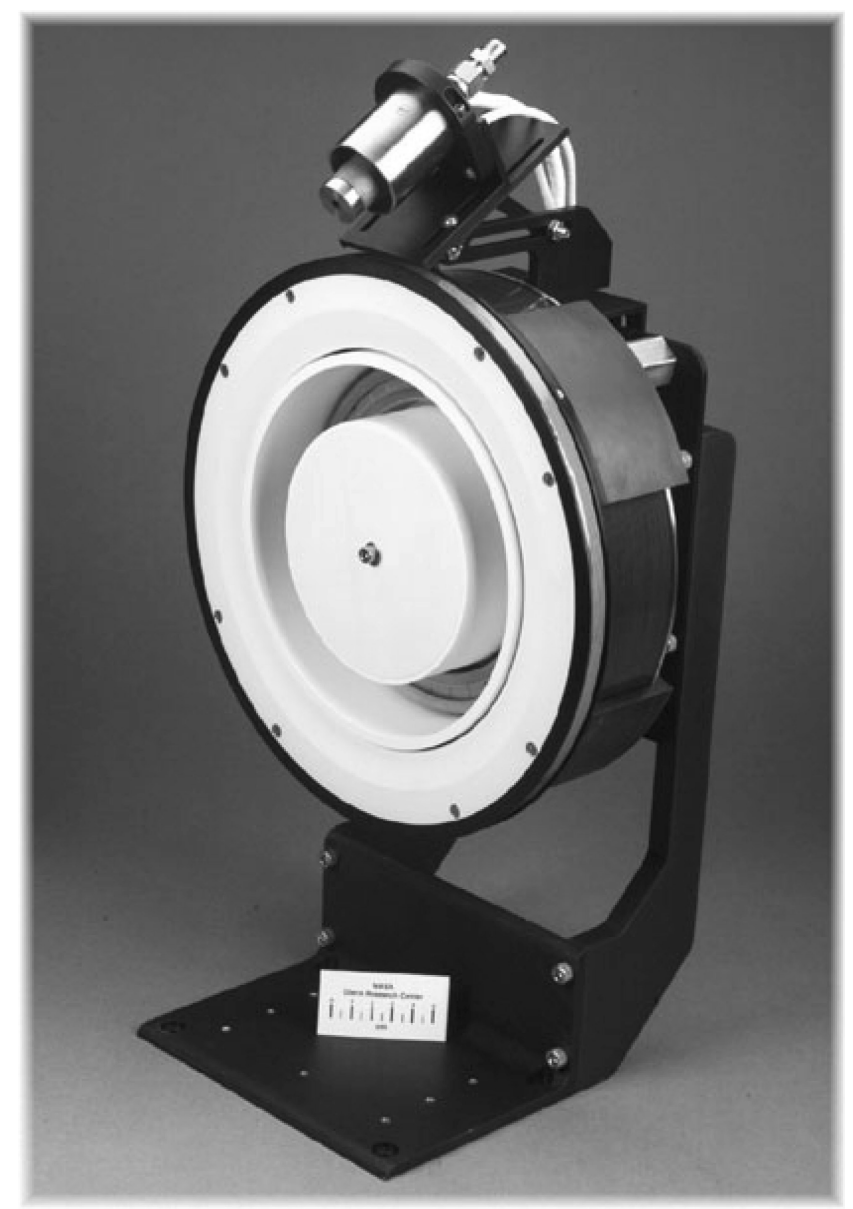

Fig. 1 High-specific impulse NASA-173Mv2 Hall thruster.

The NASA-173Mv2 is an evolved version of the NASA-173Mv1 (Ref. 29). The thrusters share the same channel geometry (outer diameter, width, and length), discharge chamber material, and gas injection scheme of the anode. The major difference between the thrusters is the shape of the magnetic field topography, which is discussed later. Other minor improvements have been made to the thermal design, assembly scheme, and mass of the NASA-173Mv2. Because these changes were not relevant to quantifying variations in thruster operation, differences in the performance and plume characteristics between the thrusters were attributed to changes in the magnetic field topography.

The magnetic field topography of the NASA-173M thrusters employ what is commonly referred to as a plasma lens. In a plasma lens, the magnetic field lines are concave and symmetric about the discharge chamber centerline. Figure 2 shows an example of the plasma lens used in the NASA-173Mv1. The plasma lens in the NASA-173Mv2 is qualitatively similar to that of the NASA$173 \mathrm{Mv} 1$. However, the lens curvature was increased and the symmetry was improved with the NASA-173Mv2. A plasma lens configuration preferentially focuses plasma away from the walls, which improves performance and thermal margin, decreases plume divergence, and increases lifetime. ${ }^{29,32,33}$ This focusing effect is possible because, to an accuracy on the order of the electron temperature, magnetic field lines form equipotentials of the applied voltage. ${ }^{34}$ The argument that magnetic field lines influence the shape of the electric field has proven to be an invaluable tool in Hall thruster design for decades. ${ }^{3}$ Numerical simulations have also successfully made use of this approximation. ${ }^{35,36}$

The NASA-173Mv2 magnetic circuit is similar to the generic Hall thruster schematic shown in Fig. 3. A fixed structure of iron pole pieces, an inner coil and an outer coil form the primary magnetic circuit. Fine control of the magnetic field is provided with an internal trim coil and an external trim coil. (As defined here, a trim coil is 


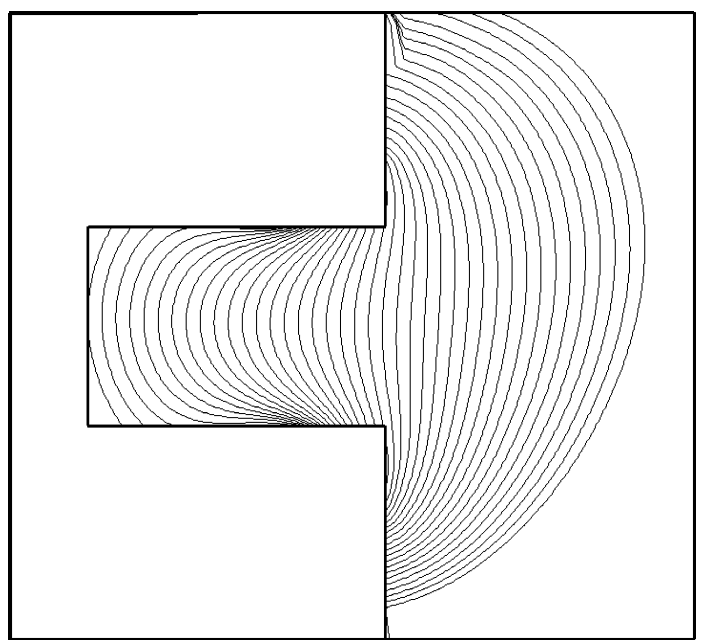

Fig. 2 NASA-173Mv1 plasma lens magnetic field topography.

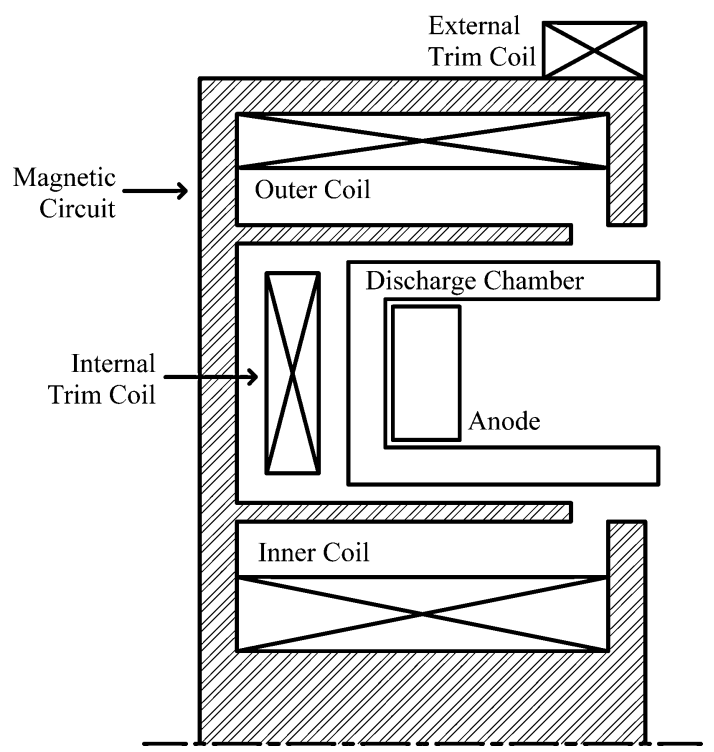

Fig. 3 Generic Hall thruster schematic (cathode excluded; not to scale).

any coil used in a Hall thruster besides the standard inner and outer coils.)

Trim coils have been used extensively in Hall thrusters for decades, dating back at least to the work of Morosov, et al. ${ }^{37,38}$ More recently, Kim, et al. has experimented with internal trim coils on xenon and krypton mixtures. ${ }^{39,40}$ Other implementations of internal trim coils are discussed in Refs. 33 and 41-43. In Ref. 44 the use of external trim coil and pole pieces to affect plume divergence and thrust vectoring is discussed.

Because of its location behind the anode (Fig. 3), the internal trim coil primarily affects the radial magnetic field in the discharge chamber. When the coil is energized, the radius of curvature of the plasma lens, that is, the axial gradient of the magnetic field, $\nabla_{z} B_{r}$, can be changed, depending on the direction of the coil current. By convention, a negative current subtracts from the magnetic field, increases the value of $\nabla_{z} B_{r}$ and increases the concavity of the plasma lens.

The external trim coil shown in Fig. 3 primarily affects the magnetic field outside of the thruster's magnetic circuit in the vicinity where the cathode is mounted and downstream of the discharge chamber exit plane. With a negative current on the external trim coil, the inclination of the magnetic field lines is increased toward the radial direction. Additional details on both internal trim coil and external trim coil may be found in Ref. 29.
The thruster was powered with commercially available power supplies. (See Ref. 29 for an electrical schematic.) A $100-\mu \mathrm{F}$ capacitor in parallel with the main discharge supply was used as the discharge filter. A laboratory-model hollow cathode rated for emission currents up to $20 \mathrm{~A}$ was used to supply electrons to the discharge chamber for ionization and the plume for neutralization. The cathode's heater and keeper were used only during the thruster ignition sequence. Xenon $(99.9995 \%$ pure) was supplied with commercially available mass flow controllers that were calibrated before each experiment using a constant-volume method. The uncertainty of the mass flow calibrations were on average $\pm 1.0 \%$. Thruster telemetry was acquired using a 22-bit datalogger that was calibrated using digital multimeters with uncertainties of $\pm 0.05 \%$ for voltage and $\pm 0.2 \%$ for current.

\section{Vacuum Facility}

All experiments were conducted in Vacuum Facility 12 (VF12) at NASA John H. Glenn Research Center (GRC). ${ }^{29}$ VF12 is a cryogenically pumped, cylindrical, stainless steel vacuum chamber that is $3 \mathrm{~m}$ in diameter and $9.6 \mathrm{~m}$ in length. The NASA-173Mv2 was always mounted on a thrust stand, with the thruster centerline near the chamber's vertical centerline, and fired $8.9 \mathrm{~m}$ down the length of the tank toward the cryopanels, which are located along the back-half of VF12. A nitrogen calibrated hot-cathode ionization gauge, which was located $5.2 \mathrm{~m}$ downstream of the thruster, recorded the background pressure. The indicated pressure measurements were corrected for xenon using the base pressure on air (typically $1.0 \times 10^{-7}$ torr) and a correction factor of 2.87 for xenon. ${ }^{29}$ For a total xenon flow rate of $11 \mathrm{mg} / \mathrm{s}$, the corrected pressure was $4.6 \times 10^{-6}$ torr.

VF12 has been used in the past for Hall thruster performance and erosion characterizations. ${ }^{45,46}$ When considering possible facility effects on performance, measurements from a 10-kW Hall thruster are a convenient reference because this thruster was tested in VF12 and in the main volume of Vacuum Facility 5 (VF5) at NASA GRC. ${ }^{45,47}$ When operating the $10-\mathrm{kW}$ thruster at xenon flow rates of $22 \mathrm{mg} / \mathrm{s}$, the pressure in VF12 was $1 \times 10^{-5}$ torr, whereas in VF5, the pressure was $2 \times 10^{-6}$ torr. Despite nearly an order of magnitude difference in pressure, the measured performance of the $10-\mathrm{kW}$ thruster in VF12 and in VF5 were equivalent (within the margin of error). This result was consistent with a study of facility effects conducted with a $5-\mathrm{kW}$ Hall thruster. ${ }^{48}$ That study concluded that neutral ingestion from the ambient tank environment has a negligible influence on performance measurements at similar tank pressures.

During testing in VF12 with the NASA-173Mv2, the maximum xenon flow rate and pressure were $16.5 \mathrm{mg} / \mathrm{s}$ (25\% less than the $10-\mathrm{kW}$ thruster) and $6.7 \times 10^{-6}$ torr, respectively. After the previous experiments in Ref. 45,47 , and 48 were considered, facility effects on the performance measurements of the NASA-173Mv2 were judged to be negligible and no corrections for facility effects were made to the thrust measurements.

\section{Thrust Stand}

Thrust measurements were acquired using a water-cooled, nullmode, inverted-pendulum thrust stand with inclination control that had been used previously with a $10-\mathrm{kW}$ Hall thruster. ${ }^{45}$ On initial exposure to vacuum, the thruster was operated for at least $2 \mathrm{~h}$ to allow for outgassing of thruster components. Thrust measurements were typically conducted at constant voltage and flow rate, in intervals of about $30 \mathrm{~min}$, following the outgassing procedure. Thermal drift during a testing interval was equivalent to no more than $0.5 \mathrm{mN}$. The uncertainty in the thrust measurements was estimated to be $\pm 0.5 \mathrm{mN}$.

During testing, if the thruster had been off for more than a few minutes, the thruster was operated for at least $30 \mathrm{~min}$ before data were collected. This ensured that the thruster and thrust stand had equilibrated sufficiently to minimize thermal drift. Repeatability was quantified by returning to select operating points over a given testing period and was influenced more by the thruster, for example, by returning to the same discharge current, than the thrust stand. 
Using these methods, the average variation in thrust for a given operating point was $\pm 1 \%$.

From the measured thrust and other telemetry (voltage, current, flow rate, etc.) the thrust-to-total power ratio, total specific impulse, and total efficiency were computed from

$$
\begin{array}{r}
T / P_{t}=\left(T / P_{d}\right) \eta_{\mathrm{mag}}=\left(T / P_{d}\right)\left(P_{d} / P_{t}\right) \\
I_{\mathrm{sp}, t}=I_{\mathrm{sp}, a} \eta_{c}=\left(T / \dot{m}_{a} g\right)\left(\dot{m}_{a} / \dot{m}_{t}\right) \\
\eta_{t}=\eta_{a} \eta_{c} \eta_{\mathrm{mag}}=\left(T^{2} / 2 \dot{m}_{a} P_{d}\right)\left(\dot{m}_{a} / \dot{m}_{t}\right)\left(P_{d} / P_{t}\right)
\end{array}
$$

Given the uncertainty of the thrust, mass flow rate, current, and voltage, the propagated uncertainty for specific impulse was $\pm 1.4 \%$ and $\pm 2.3 \%$ for efficiency. For example, if the measured specific impulse and efficiency were $1600 \mathrm{~s}$ and 0.500 , respectively, then the absolute uncertainty would be $\pm 22 \mathrm{~s}$ and \pm 0.012 .

\section{Faraday Probe}

Azimuthal surveys of the ion current density were taken in the thruster's plume using a Faraday probe that had been characterized previously. ${ }^{45,49,50}$ Shown schematically in Fig. 4, the probe consisted of a 1.94-cm-diam collection electrode enclosed within a 3.20-cm-diam guard ring. The guard ring and collector were separated by a $0.14-\mathrm{cm}$ gap, were made from molybdenum, and were biased $-15 \mathrm{~V}$ below facility ground to repel electrons. Biasing the guard ring and collector to the same potential minimized edge effects around the collector by creating a flat, uniform sheath such that the effective collection area could be taken as the geometric area of the collection electrode. The probe face was aligned $98.5 \pm 0.5 \mathrm{~cm}$ downstream of the exit plane, with the axis of rotation located on thruster centerline at the exit plane. An angular coordinate system was defined such that thruster centerline was referenced as $0 \mathrm{deg}$. When viewed downstream from the exit plane, angles became increasingly positive when the probe was swept clockwise. Sweeps were performed from -100 to $+100 \mathrm{deg}$ in 1-deg increments. At each location, 1000 data points were sampled at $1 \mathrm{kHz}$ and averaged using a 16-bit data acquisition card.

Angular profiles of the ion current density were used to compute the average plume divergence half-angle $\bar{\beta}_{95}$. The divergence angle was computed separately over positive and negative angles and then averaged. A positive plume divergence angle $+\beta_{95}$ and a negative plume divergence angle $-\beta_{95}$ were computed as the half-angle from centerline over which the ion current density integrated to $95 \%$ of the ion current density integrated from centerline to +90 or $-90 \mathrm{deg}$, respectively. That is, the divergence angles were given by

$$
0.95 \int_{0}^{ \pm 90} j(\theta) \sin (\theta) \mathrm{d} \theta=\int_{0}^{ \pm \beta_{95}} j(\theta) \sin (\theta) \mathrm{d} \theta
$$

The difference between positive and negative angles and the average angle was never more than $4.0 \%$, and the average difference was $1.3 \%$.

Nude Faraday probes overestimate the ion current density due to the presence of low-energy charge exchange (CEX) ions. The effects of plume CEX ions are most evident at high angles from thruster centerline, where the CEX ions overwhelm the current from the main beam ions resulting in "wings" in the data (Fig. 5). Experimental and numerical studies of backpressure effects on Hall thruster plumes

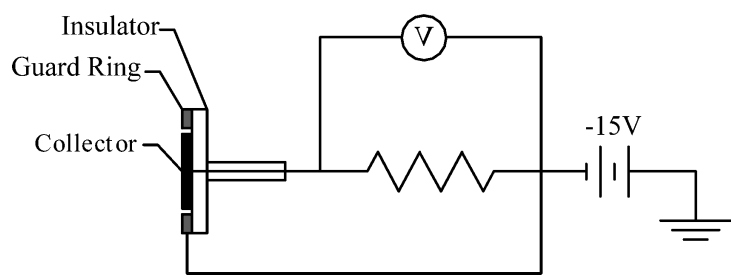

Fig. 4 Faraday probe electric schematic.

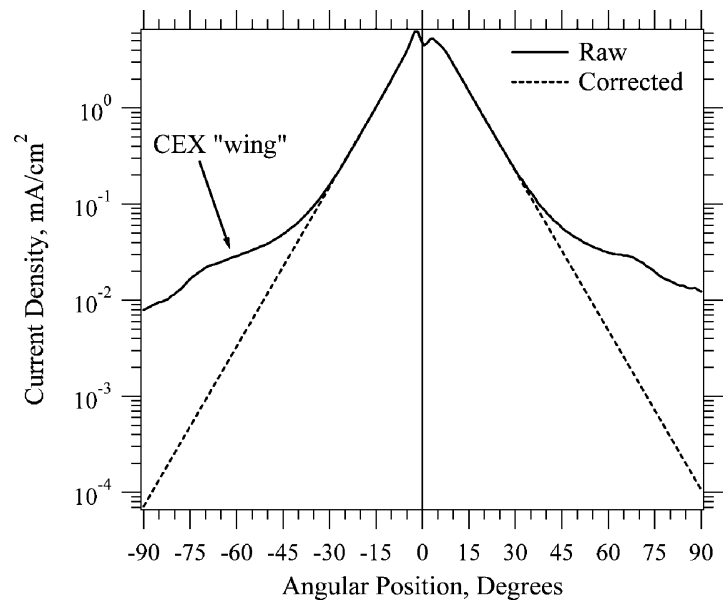

Fig. 5 Plume ion current density vs angular position from thruster centerline at $10 \mathrm{mg} / \mathrm{s}, 1000 \mathrm{~V}$ (ITC, ETC). Raw data taken with Faraday probe. Corrected data removes the CEX wings for angles greater than 30 deg.

have shown that these wings are an artifact of the facility backpressure that would not be encountered on-orbit and should, therefore, be excluded from the measurement. ${ }^{49-51}$ The probe used in this study was incapable of differentiating between CEX ions and main beam ions, and so to account for the CEX ions the exponentially decreasing portion of the data between 10 and 30 deg were extrapolated to $90 \mathrm{deg}$ (Fig. 5). ${ }^{52}$ The resulting profiles were then integrated to obtain the plume divergence half-angle using Eq. (4). Measurement uncertainty of the plume divergence angle was conservatively estimated as $\pm 20 \%$.

\section{Discharge Current Probe}

An 8-bit, 500-MHz oscilloscope and a 50-MHz current probe were used to measure discharge current oscillations with an accuracy of $\pm 3 \%$. The probe was located on the anode side of the discharge power supply after the $100-\mu \mathrm{F}$ capacitor described earlier. The oscilloscope sampled the discharge current at $250 \mathrm{kHz}$ for $2 \mathrm{~ms}$. Oscillations were quantified by calculating the standard deviation of the discharge current over the sampling period. The power spectral density of the discharge current was computed from the discrete Fourier transform with Parzen windowing. Oscillations at frequencies of $10-30 \mathrm{kHz}$ are usually attributed to the breathingmode ionization instability. ${ }^{35,53}$ (Breathing-mode oscillations result from the periodic depletion of neutral propellant due to ionization.) The breathing-mode ionization instability was identified as the frequency at which the magnitude of the power spectrum was greatest in the $10-30 \mathrm{kHz}$ frequency range. Measurement uncertainty of the breathing-mode frequency was $\pm 1 \mathrm{kHz}$.

\section{Results and Discussion}

Several experiments were conducted to explore the operating characteristics of the NASA-173Mv2. First, a performance evaluation was conducted to quantify the effects of current density and magnetic field topography on thruster efficiency at high-specific impulse. With use of the coil currents identified in the performance measurements that maximized thruster efficiency, additional experiments were conducted to measure the ion current density of the plume and discharge current oscillations.

The effects of changing the magnetic field topography on thruster operation were investigated by energizing the thruster coils in different combinations. The coil combinations subsequently shown are labeled as 1) inner coil, outer coil, only the inner coil and outer coil were energized; 2) internal trim coil, the internal trim coil was energized in addition to the inner coil and outer coil; 3) internal trim coil, external trim coil, both trim coils were energized in addition to the inner coil and outer coil, and 4) external trim coil, the external trim coil was energized in addition to the inner coil and outer coil. 


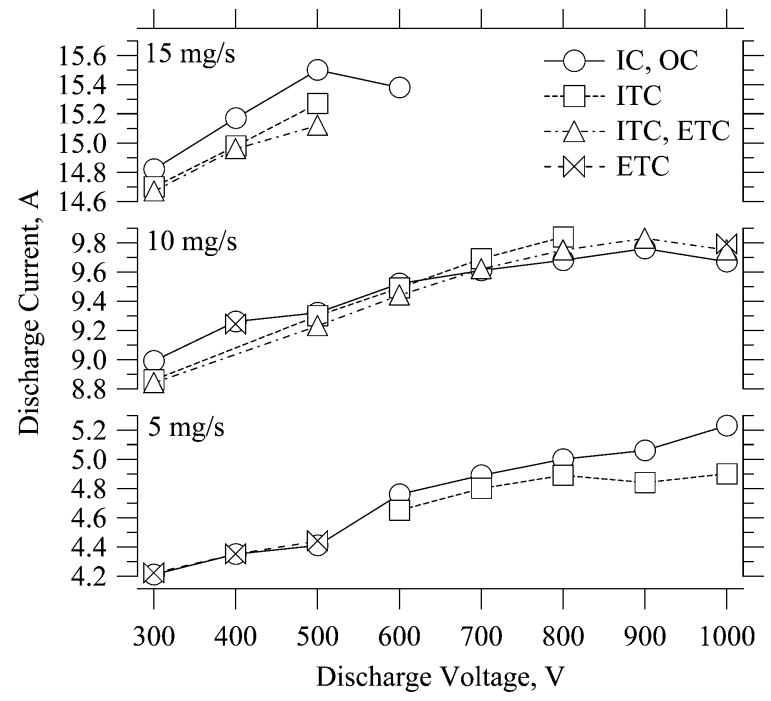

Fig. 6 Discharge current vs discharge voltage at 5,10 , and $15 \mathrm{mg} / \mathrm{s}$.

\section{Performance}

Performance of the NASA-173Mv2 was evaluated over $300-1000 \mathrm{~V}$ at 5 and $10 \mathrm{mg} / \mathrm{s}$ and $300-600 \mathrm{~V}$ at $15 \mathrm{mg} / \mathrm{s}$. The thruster operating points are shown in the current-voltage characteristic shown in Fig. 6. Performance data are tabulated in Ref. 29.

The cathode flow rate was maintained at $10 \%$ of the anode flow rate to ensure there was a sufficient supply of electrons for neutralization and ionization. No attempts were made to optimize the cathode flow or cathode position, or to minimize the power dissipation of the coils.

The general method for taking data was to set the voltage and flow rate and then investigate the effects of each coil on discharge current, discharge current oscillations, and anode efficiency. It was observed that the effects of the internal and external trim coils on performance were nearly independent. Therefore, it was decided to record data first with the internal trim coil energized, then with both trim coils. This method was used only when both trim coils increased efficiency. For example, if the internal trim coil showed no efficiency benefit, only external trim coil data were collected.

After the general range of coil currents yielding near-optimum efficiency was determined, data were recorded at several coil currents in this range to ensure that performance was indicative of the optimum. Only data at the coil currents resulting in maximum efficiency are reported here. Maximum efficiency was generally realized where the discharge current and oscillations were minimized. However, there were cases when the discharge current would increase with efficiency when the trim coils were energized, which are discussed later in this section.

The thruster was stable and capable of sustained operation (from tens of minutes to hours) during the period when data at a given operating point were recorded. At discharge voltages greater than $300 \mathrm{~V}$, thruster stability was reduced for $10-30 \mathrm{~min}$ after the voltage was initially increased. This behavior was attributed to the movement of the plasma toward the anode that resulted in a gradual lengthening of the discharge chamber erosion band as deposits on the channel walls were gradually eroded away through ions impacting the wall. A burnoff period at $600 \mathrm{~V}$ or more first confirmed this. Probe diagnostics (not shown) have also confirmed that the discharge chamber plasma shifts toward the anode as the voltage increases. ${ }^{54,55}$ Burnoff was qualified by visually observing the erosion layer glowing orange-red at its upstream boundary. Although burnoff was observed only above $600 \mathrm{~V}$, it most likely occurred to a lesser extent at all voltages. Burnoff was quantified by an increase in the discharge current and a decrease in efficiency. The thruster was unstable during burnoff unless the coil currents were increased by a few amperes (typically by $0.5-2.0 \mathrm{~A}$ above nominal currents ranging from 1.5 to $4.5 \mathrm{~A}$ ). After the 10-30 min burnoff period at each voltage, the coil currents could be reduced and the thruster returned

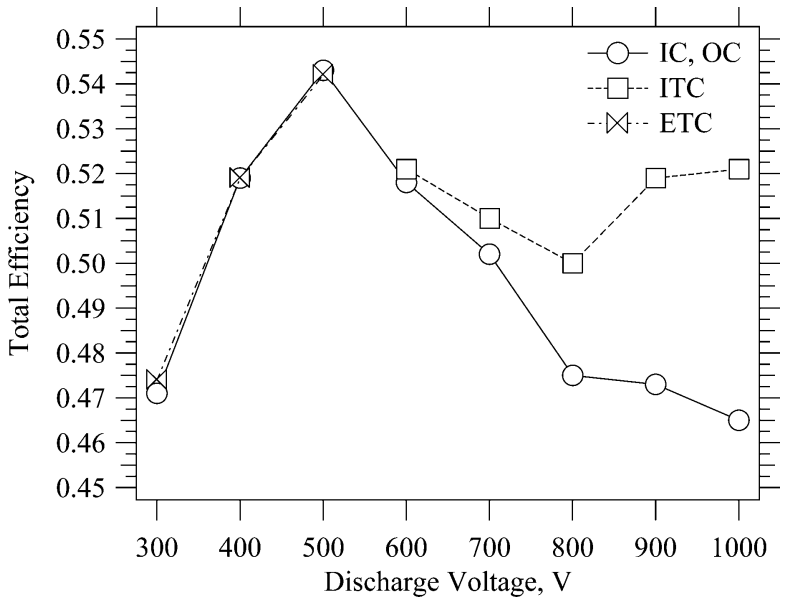

Fig. 7 Total efficiency vs discharge voltage at $5 \mathrm{mg} / \mathrm{s}$.

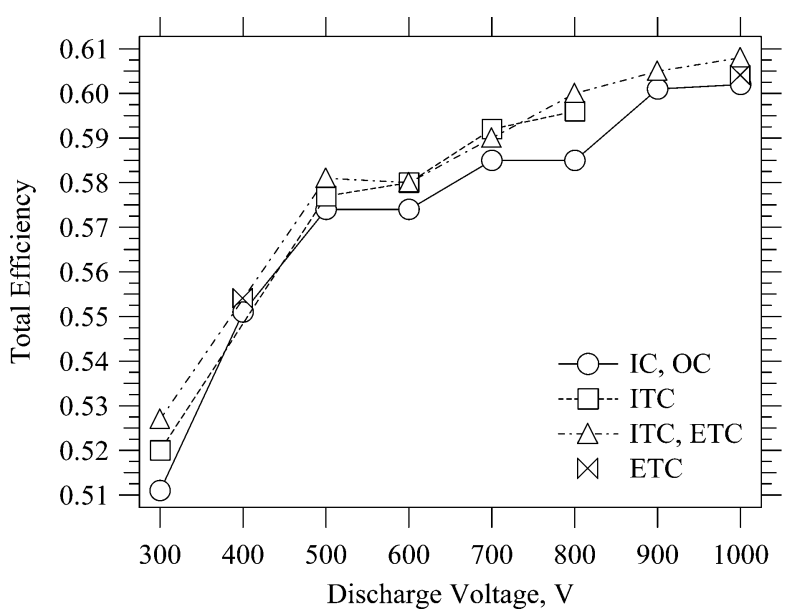

Fig. 8 Total efficiency vs discharge voltage at $10 \mathrm{mg} / \mathrm{s}$.

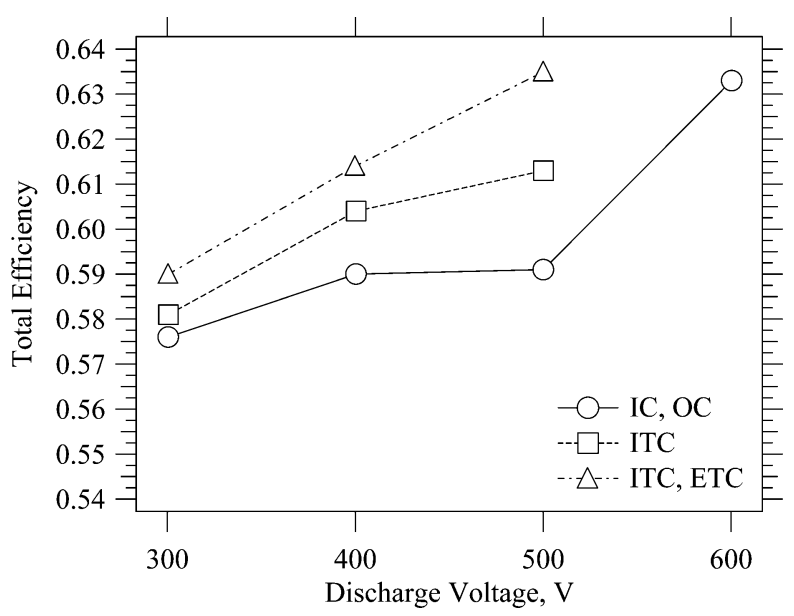

Fig. 9 Total efficiency vs discharge voltage at $15 \mathrm{mg} / \mathrm{s}$.

to a stable operating mode. Discharge current also decreased after burnoff and the efficiency increased.

Figures 6-9 show how changing the magnetic field with the trim coils influenced thruster operation. Specifically, Fig. 6 shows the current-voltage characteristics and Figs. 7-9 plot total efficiency vs discharge voltage. Figures 10-13 show the performance parameters from the coil combinations in Figs. 7-9 that maximized total efficiency at each operating point. Over all operating conditions, thrust varied from 81 to $442 \mathrm{mN}$, the thrust-to-total power ratio varied from 31 to $66 \mathrm{mN} / \mathrm{kW}$, total specific impulse varied from 1510 to $3390 \mathrm{~s}$, and total efficiency varied from 47.1 to $63.5 \%$. 


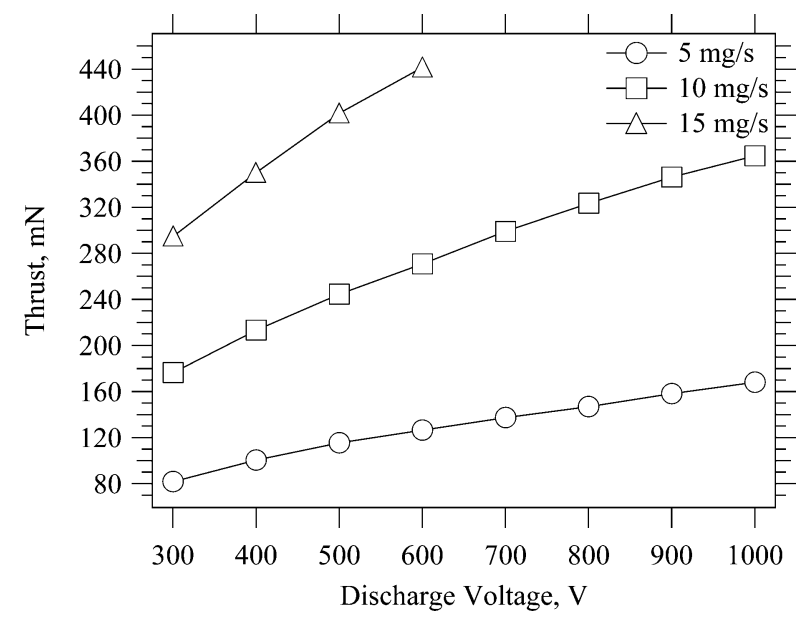

Fig. 10 Optimized thrust vs discharge voltage at 5,10 , and $15 \mathrm{mg} / \mathrm{s}$.

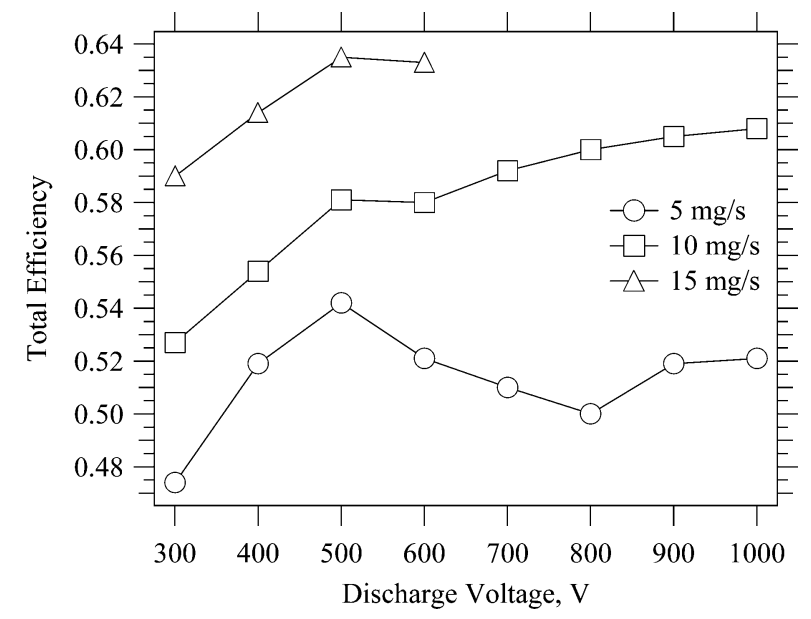

Fig. 11 Optimized total efficiency vs discharge voltage at 5,10 , and $15 \mathrm{mg} / \mathrm{s}$.

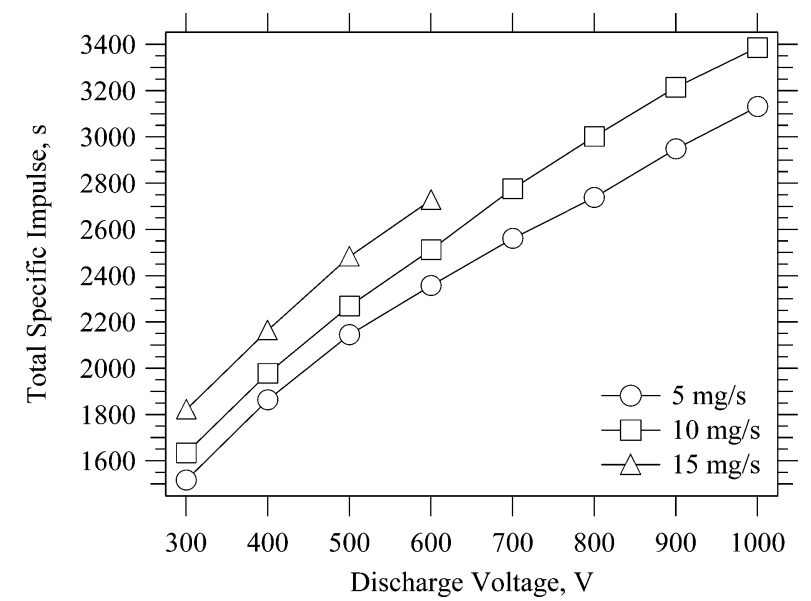

Fig. 12 Optimized total specific impulse vs discharge voltage at 5,10 , and $15 \mathrm{mg} / \mathrm{s}$.

The functional relationship of the discharge voltage and current is shown in Fig. 6 for flow rates of 5, 10, and $15 \mathrm{mg} / \mathrm{s}$, respectively. At constant flow rate, the current was found to increase slowly with voltage. At a fixed discharge voltage, energizing the trim coils generally reduced the discharge current and increased thrust. Exceptions to this trend were at $700-1000 \mathrm{~V}$ at $10 \mathrm{mg} / \mathrm{s}$. At these operating points, changing the magnetic field with the trim coils increased the discharge current and thrust. Increased discharge current could

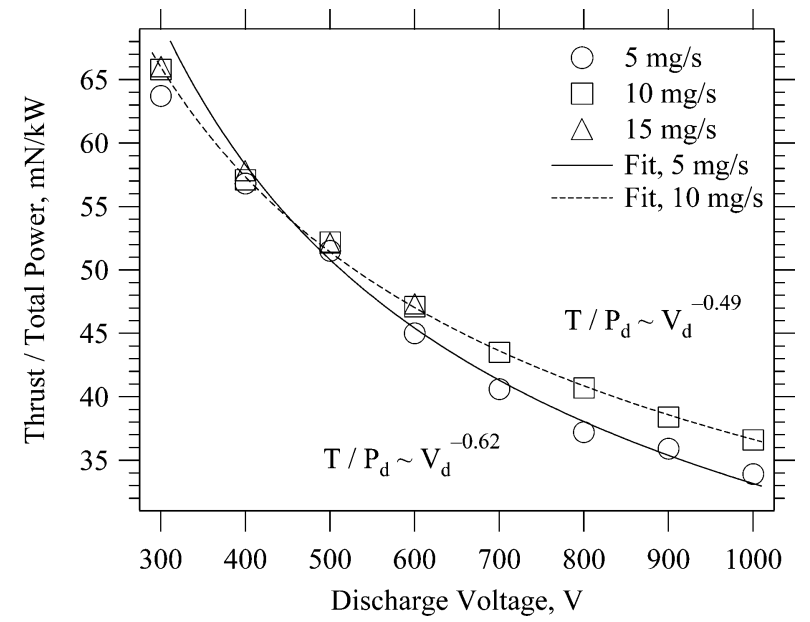

Fig. 13 Optimized thrust-to-total power ratio vs discharge voltage at 5,10 , and $15 \mathrm{mg} / \mathrm{s}$.

result from either a rise in the ion or electron current. However, probe diagnostics have shown that the rise in discharge current was primarily due to increased ion current resulting from the fraction of multiply charged ions increasing with voltage. ${ }^{56}$

Figures 7-9 show total efficiency versus discharge voltage for flow rates of 5,10 , and $15 \mathrm{mg} / \mathrm{s}$, respectively. At a given flow rate and voltage, efficiency was improved or remained unchanged by using the trim coils. When efficiency was unchanged, there were still performance benefits because thrust usually increased.

As shown in Fig. 7, at $5 \mathrm{mg} / \mathrm{s}$, total efficiency spanned the range from $47.1 \%$ at $300 \mathrm{~V}$ to $52.1 \%$ at $1000 \mathrm{~V}$. The maximum total efficiency was $54.3 \%$, which occurred at $500 \mathrm{~V}$. Efficiency at $5 \mathrm{mg} / \mathrm{s}$ shows trends that were very similar to the NASA-173Mv1 (not shown, see Ref. 29). Both thrusters reached a maximum efficiency, despite the use of trim coils, which occurred at $500 \mathrm{~V}$ in the NASA$173 \mathrm{Mv} 2$ and $600 \mathrm{~V}$ in the NASA-173Mv1. At voltages greater than the voltage where maximum efficiency occurred, trim coils improved efficiency, but at best the efficiency reached an asymptote with increased voltage.

When trim coils were used at $5 \mathrm{mg} / \mathrm{s}$, the improvement in efficiency was greatest at the highest voltages. For example, for the NASA-173Mv2 at $300 \mathrm{~V}$ trim coils improved efficiency by $0.6 \%$ (absolute), whereas at $1000 \mathrm{~V}$ efficiency increased by $5.6 \%$ (absolute). Furthermore, positive internal trim coil currents were found to improve efficiency in the NASA-173Mv2 at $5 \mathrm{mg} / \mathrm{s}$, whereas negative currents were always beneficial in the NASA-173Mv1. Recall that positive internal trim coil current decreases $\nabla_{z} B_{r}$ along the channel. Because $\nabla_{z} B_{r}$ is greater in the NASA-173Mv2 than the NASA-173Mv1, this implies there is an optimum value of $\nabla_{z} B_{r}$ at $5 \mathrm{mg} / \mathrm{s}$, which can be determined by comparing the magnetic fields in both thrusters.

It is significant that the relative variation of the efficiency at $5 \mathrm{mg} / \mathrm{s}$ was nearly identical between the thrusters despite that the magnetic field topographies were different. This strongly suggested that current density was the dominant factor affecting efficiency at $5 \mathrm{mg} / \mathrm{s}$ and that the influence of the magnetic field on thruster efficiency was second order. Above a critical flow rate, the influence of current density diminished and the magnetic field influence was dominant. This was shown by the efficiency maximum being eliminated in the NASA-173Mv2 but not in the NASA-173Mv1 for flow rates of $10 \mathrm{mg} / \mathrm{s}$. (See Fig. 14 and discussion later in this section for more detail.) In short, current density and magnetic field topography both have important roles in achieving efficient operation at high-specific impulse.

Figure 8 shows that total efficiency at $10 \mathrm{mg} / \mathrm{s}$ increased monotonically with voltage. Total efficiency at $10 \mathrm{mg} / \mathrm{s}$ spanned the range from $51.1 \%$ at $300 \mathrm{~V}$ to $60.8 \%$ at $1000 \mathrm{~V}$. Efficiency at $10 \mathrm{mg} / \mathrm{s}$ increased with voltage whether or not the trim coils were used, which indicated improvements to the magnetic field in the NASA$173 \mathrm{Mv} 2$ with respect to the NASA-173Mv1 were near the optimum 


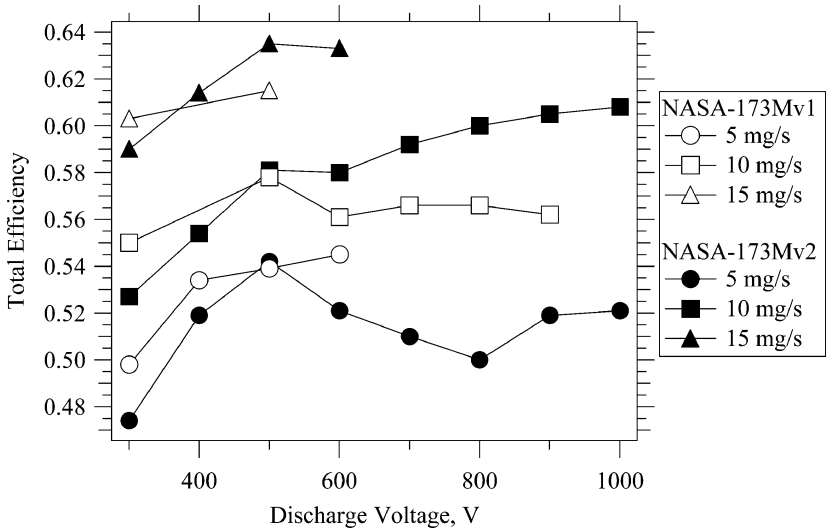

Fig. 14 Total efficiency vs discharge voltage of the NASA-173Mv1 (open symbols) and the NASA-173Mv2 (filled symbols) Hall thrusters: $\bigcirc$ and $\bullet, 5 \mathrm{mg} / \mathrm{s} ; \square$ and $\square, 10 \mathrm{mg} / \mathrm{s}$; and $\triangle$ and $\Delta, 15 \mathrm{mg} / \mathrm{s}$.

for high-specific impulse operation. Unlike the data at $5 \mathrm{mg} / \mathrm{s}$ in Fig. 7 that show efficiency improved by as much as 5.6\% (absolute), using trim coils at $10 \mathrm{mg} / \mathrm{s}$ improved efficiency by an average of only $0.8 \%$ (absolute) and the maximum increase was $1.6 \%$ (absolute). Overall, differences between the 5 and $10 \mathrm{mg} / \mathrm{s}$ efficiency data imply there is a minimum current density necessary for highefficiency operation.

In Fig. 9, the efficiency at $15 \mathrm{mg} / \mathrm{s}$ shows trends that are similar to the $10 \mathrm{mg} / \mathrm{s}$ data shown in Fig. 8, albeit at higher efficiencies. Total efficiency at $15 \mathrm{mg} / \mathrm{s}$ spanned the range from $59.0 \%$ at $300 \mathrm{~V}$ to $63.3 \%$ at $600 \mathrm{~V}$. Anode efficiencies exceeded $70 \%$ at $500-600 \mathrm{~V}$. Data were not acquired above $600 \mathrm{~V}$ because it was decided to reduce the risk of thermal failure by limiting the maximum discharge power to $10 \mathrm{~kW}$.

Optimized values of the thrust, total efficiency, total specific impulse, and the thrust-to-total power ratio $\left(T / P_{t}\right)$, for flow rates of 5,10 , and $15 \mathrm{mg} / \mathrm{s}$ are shown in Figs. 11-13. At each operating point, the coil combinations corresponding to maximum thruster efficiency from Figs. 7-9 are shown.

Figure 10 shows the optimized thrust produced by the NASA$173 \mathrm{Mv} 2$ at each voltage and flow rate that were investigated. As expected, thrust increased with the mass flow rate and voltage because $T \propto \dot{m}_{a} \times V_{d}^{1 / 2}$.

Figure 11 shows the optimized total efficiency at each flow rate. At $10 \mathrm{mg} / \mathrm{s}$, total efficiency exceeded $60 \%$ at $800 \mathrm{~V}$. The maximum total efficiency was $63.5 \%$ at $500 \mathrm{~V}, 15 \mathrm{mg} / \mathrm{s}$. Trends in total efficiency emphasize the importance of current density in achieving optimal performance. At a fixed voltage, efficiency improved at each higher flow rate because the ionization rate is known to be proportional to the neutral density. ${ }^{2,3}$ At fixed mass flow rate, current density also has a role in optimizing efficiency with increasing voltage, as shown by the contrasting efficiency characteristics at 5 and $10 \mathrm{mg} / \mathrm{s}$.

Figure 12 shows the optimized total specific impulse at each flow rate. At $10 \mathrm{mg} / \mathrm{s}$, greater than 3000-s total specific impulse was demonstrated at $800 \mathrm{~V}$. The maximum total specific impulse was $3390 \mathrm{~s}$ at $1000 \mathrm{~V}, 10 \mathrm{mg} / \mathrm{s}$. The specific impulse also increased, like efficiency, with current density at a fixed voltage because of improved mass utilization. However, unlike efficiency, specific impulse always increased with voltage at constant mass flow rate. This was because thrust always increased with voltage (Fig. 10), and the thrust and specific impulse ideally scale with discharge voltage as $T \propto I_{\mathrm{sp}} \propto V_{d}^{1 / 2}$.

Trends in efficiency and specific impulse are best understood by considering the $T / P_{t}$ ratio, shown in Fig. 13 . The $T / P_{t}$ ratio showed a weak dependence with current density between 300 and $500 \mathrm{~V}$. At $600 \mathrm{~V}$ or above, the $T / P_{t}$ ratio at $5 \mathrm{mg} / \mathrm{s}$ decreased faster than at $10 \mathrm{mg} / \mathrm{s}$, which corresponded to the decrease in efficiency shown in Fig. 11. At a constant flow rate, efficiency ideally scales as $\eta \propto T^{2} / P_{t} \propto T / P_{t} \times V_{d}^{1 / 2}$. Thus, if the $T / P_{t}$ ratio scales with voltage at a power of less than $-\frac{1}{2}$, the efficiency will decrease.
A power law curve fit to the $5 \mathrm{mg} / \mathrm{s}$ data in Fig. 13 shows that $T / P_{t} \propto V_{d}^{-0.62}$, whereas the 10-mg/s data scales as $T / P_{t} \propto V_{d}^{-0.49}$. This shows that the decrease in efficiency observed at $5 \mathrm{mg} / \mathrm{s}$ was the result of increased electron current, rather than a decrease in ion current or a large increase in multiply charged ions.

Figure 14 shows a comparison of the total efficiency for the NASA-173M Hall thrusters at anode flow rates of 5, 10, and $15 \mathrm{mg} / \mathrm{s}$. The NASA-173Mv1 data were acquired using an identical experimental setup as the NASA-173Mv2. The data show that thruster efficiency can be maximized by controlling both current density and magnetic field topography, each of which are discussed next.

Current density was shown to affect efficiency in two ways. First, at constant voltage the efficiency of both thrusters benefited from increased propellant utilization as the flow rate increased. Second, current density played a critical role with the variation of efficiency with voltage. This is shown in the data from the NASA-173Mv2, where thruster efficiency monotonically increased at $10 \mathrm{mg} / \mathrm{s}$, whereas at $5 \mathrm{mg} / \mathrm{s}$ a peak efficiency was observed.

Magnetic field topography also played a crucial role in optimizing efficiency. This was shown by considering the variation of efficiency with voltage for both thrusters at $10 \mathrm{mg} / \mathrm{s}$. With the NASA-173Mv1 at $10 \mathrm{mg} / \mathrm{s}$, efficiency showed evidence of a maximum at $500 \mathrm{~V}$, and then at higher voltages, efficiency was relatively constant. In contrast, the efficiency of the NASA-173Mv2 at $10 \mathrm{mg} / \mathrm{s}$ monotonically increased with increasing voltage. The only major difference between the thrusters was the shape of the magnetic field lines because the magnitude of the magnetic field was nearly the same (not shown, see Ref. 29). From these results, it was concluded that changes made to the magnetic circuit of the NASA-173Mv2 were responsible for eliminating the efficiency peak. That is, the NASA$173 \mathrm{Mv} 2$ achieved the intended goal of optimizing the magnetic field topography for high-specific impulse operation.

Figure 14 also shows that thruster efficiency can be optimized for specific impulse by changing the plasma lens design. At $10 \mathrm{mg} / \mathrm{s}$, the efficiency of the NASA-173Mv2 was higher than the NASA$173 \mathrm{Mv} 1$ for discharge voltages greater than $500 \mathrm{~V}$. At 5 and $15 \mathrm{mg} / \mathrm{s}$, the NASA-173Mv1 efficiency showed the same trend of being more efficient at low voltages (although data were limited at these flow rates). Thus, differences in the magnetic field topography of the NASA-173M Hall thrusters have shown how thruster efficiency can be optimized for specific impulse.

\section{Ion Current Density}

Ion current density and discharge current oscillation data (discussed in the next section) were collected concurrently after determining optimum coil currents from the performance characterization. Measurements of the ion current density were made at $10 \mathrm{mg} / \mathrm{s}$ between voltages of 300 and $1000 \mathrm{~V}$. At each voltage, plume profiles with the inner coil and outer coil alone were measured. At 300$600 \mathrm{~V}$, the internal trim coil and the combined influence of both trim coils were documented. At 700-1000 V, only data with both trim coils energized were collected, with the exception of $1000 \mathrm{~V}$, which included a data set with the external trim coil.

Figure 15 shows results from 300-600 V and Fig. 16 includes data from 700-1000 V. Figures 15 and 16 both include only data with both trim coils energized. Differences in the plume profiles with the other coils were quantified by calculating the plume divergence angle. Figure 17 shows the plume divergence half-angle vs discharge voltage for all of the coil combinations that were investigated.

The double peak structure of the ion current density profiles in Figs. 15 and 16 was attributed to the annular geometry of the discharge chamber. The current density peaks were more pronounced as the voltage increased, indicating more of the ion current was located near centerline. It is likely that the asymmetry in the profiles was the result of azimuthal nonuniformity of the neutral gas distribution through the anode. Asymmetries in the gas flow can grossly affect thruster operation by severely reducing the performance, stability, and thermal margin. ${ }^{29}$ However, based on the favorable performance, stability, and thermal margin of the NASA$173 \mathrm{Mv} 2$, asymmetries in the plume profiles were judged to affect thruster operation only marginally. 


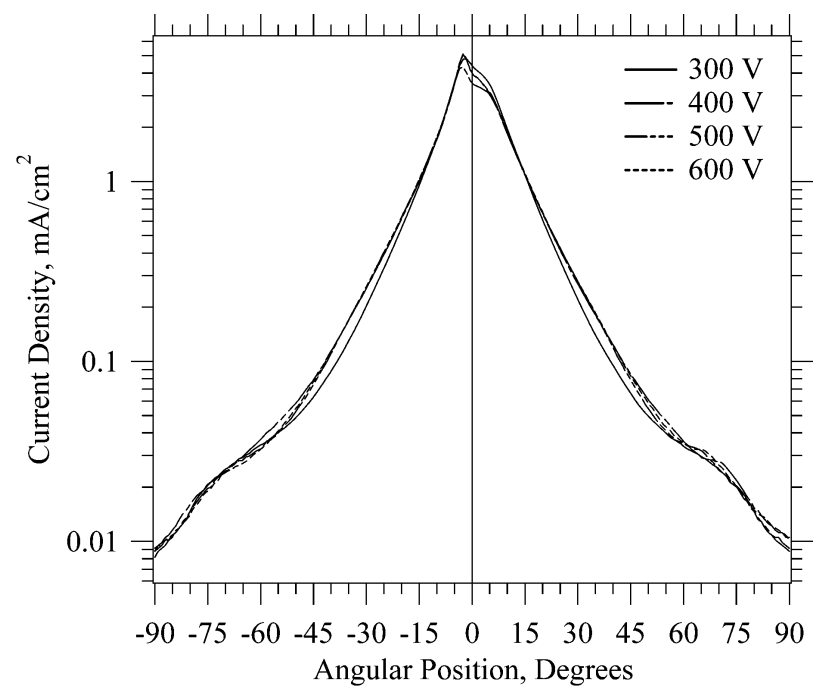

Fig. 15 Plume ion current density vs angular position from thruster centerline at $10 \mathrm{mg} / \mathrm{s}, 300-600 \mathrm{~V}$ (ITC, ETC).

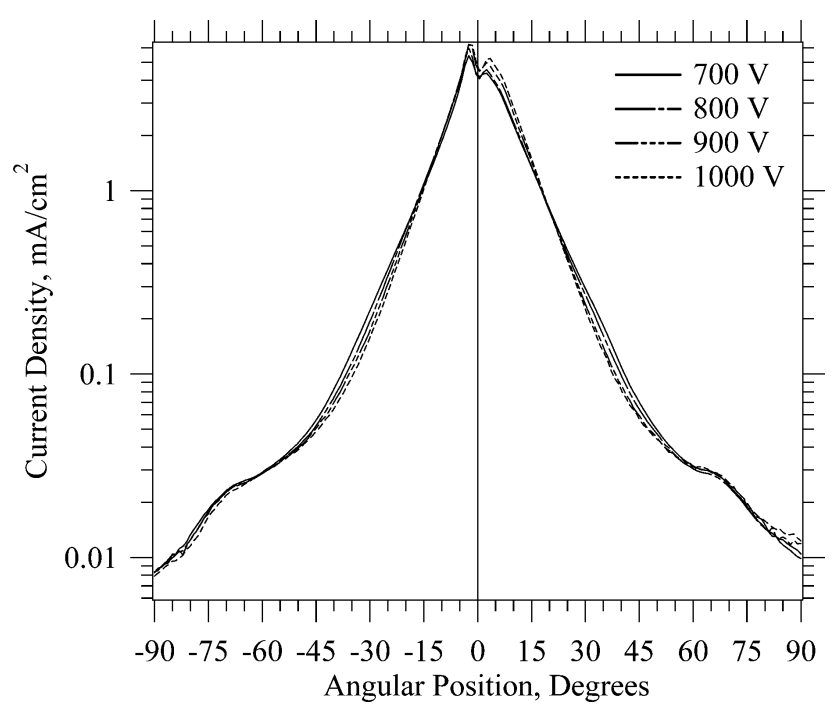

Fig. 16 Plume ion current density vs angular position from thruster centerline at $10 \mathrm{mg} / \mathrm{s}, 700-1000 \mathrm{~V}$ (ITC, ETC).

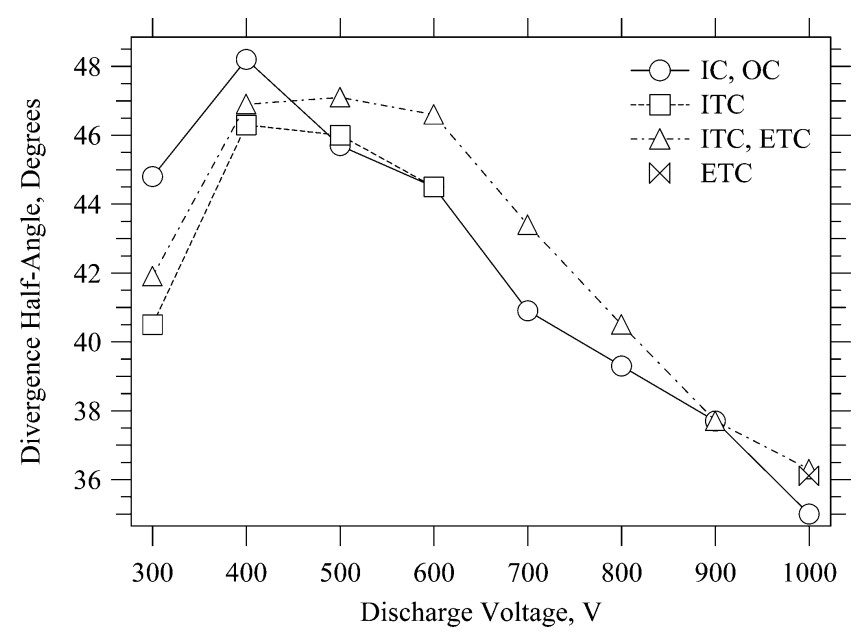

Fig. 17 Plume divergence half-angle vs discharge voltage at $10 \mathrm{mg} / \mathrm{s}$.

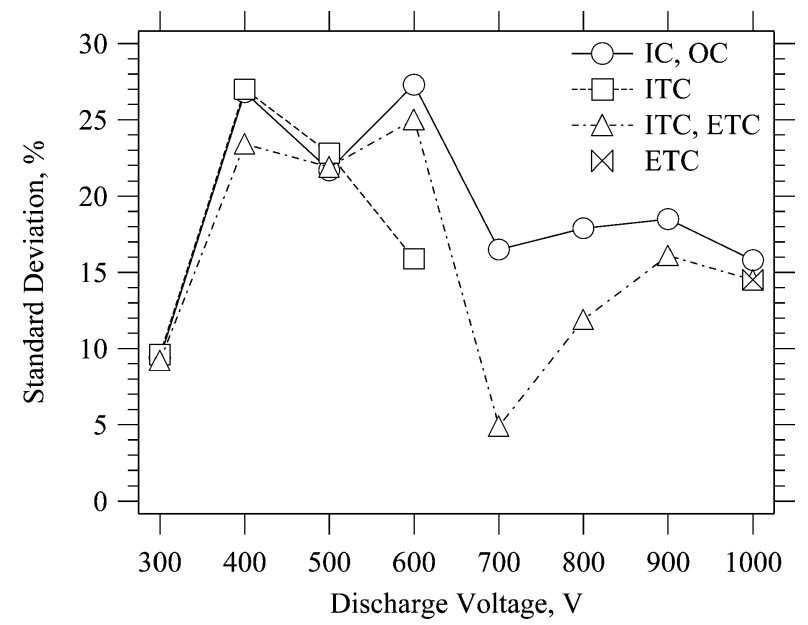

Fig. 18 Standard deviation of discharge current oscillations vs discharge voltage at $10 \mathrm{mg} / \mathrm{s}$.

As shown in Fig. 17, plume divergence increased between 300 and $400 \mathrm{~V}$ to a maximum of $48 \mathrm{deg}$ at $400 \mathrm{~V}$ and then steadily decreased to the minimum of $35 \mathrm{deg}$ at $1000 \mathrm{~V}$. The initial increase between 300 and $400 \mathrm{~V}$ was attributed to a large increase in discharge current oscillations from 9 to $27 \%$ (Fig. 18; see next section for further discussion on oscillations). Plume divergence is determined by a number of processes, including radial electric fields in the acceleration zone, the axial location of the ionization and acceleration zones, thermal spreading at the ion acoustic velocity, particle collisions in the plume, and plasma oscillations. ${ }^{2,53,57}$ How these processes scale, and which ones dominate, is not completely understood, but divergence should scale as the ratio of radial to axial ion velocity if the influence of plume collisions and plasma oscillations can be neglected and the location of the plasma in the discharge chamber is constant. If this were the case, the decreasing divergence angle measured between 400 and $1000 \mathrm{~V}$ would imply that axial velocities increased at a faster rate than radial velocities, which should benefit thruster lifetime. The reduction in divergence could also be attributed to the upstream movement of the plasma with increased discharge voltage reported here and in Refs. 54 and 55. However, this would imply higher wall losses and decreased efficiency. Because efficiency increased with increasing voltage (Fig. 8), it seems more likely that the decreased divergence with voltage resulted from a decreasing ratio of radial to axial ion velocities. Additional measurements are needed to better understand the reduction in plume divergence with increasing voltage.

With few exceptions, Fig. 17 shows that the external trim coil increased divergence, whereas the internal trim coil decreased divergence. For example, between 300 and $600 \mathrm{~V}$ divergence decreased with the internal trim coil and then increased when the external trim coil was added. Insight on how the external trim coil affected the plasma was gained by considering data tabulated in Ref. 29 of the cathode potential (a measure of the electron coupling with the discharge), which showed that the external trim coil increased the cathode potential, that is, decreased the magnitude with respect to ground. Taken together, the divergence and cathode potential trends indicated that the external trim coil improved efficiency by acting primarily on the electrons. Probe measurements taken within one thruster diameter of the thruster exit plane have also supported this conclusion. $^{29}$

The effects of the internal trim coil are more complex than the external trim coil because the internal trim coil alters the magnetic field inside the discharge chamber. Figure 17 shows that the internal trim coil decreased divergence, whereas the data tabulated in Ref. 29 show (with few exceptions) that the cathode potential became more negative, the discharge current decreased, and the thrust increased. The changes in cathode potential and discharge current implied the internal trim coil decreased the axial electron current, whereas the increase in thrust suggested that the ion focusing was improved when the internal trim coil was used. 


\section{Discharge Current Oscillations}

Discharge current oscillations at $10 \mathrm{mg} / \mathrm{s}$ were measured between 300 and $1000 \mathrm{~V}$ at the same coil combinations as the ion current density from the preceding section. The power spectral density, breathing-mode frequency, and the standard deviation of the oscillations (expressed as a percentage of the mean discharge current) were computed from the data. Power spectra at 300 and $1000 \mathrm{~V}$ are shown in Figs. 19 and 20, respectively. In Figs. 21 and 18, the voltage dependence of the breathing-mode frequency and the standard deviation of the oscillations are shown, respectively.

As shown in Figs. 19 and 20, energizing the trim coils affected the power spectra at 300 and $1000 \mathrm{~V}$. Figure 19, at $300 \mathrm{~V}$, shows how the broadband distribution without trim coils was replaced by a

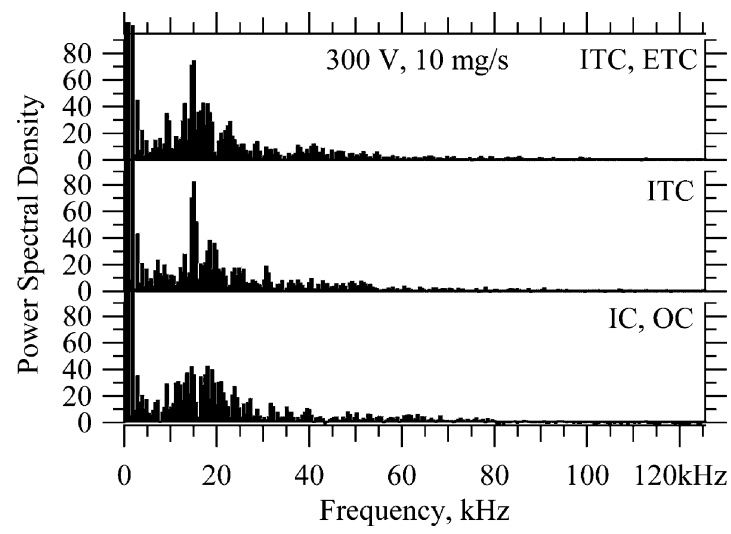

Fig. 19 Discharge current power spectra at $300 \mathrm{~V}, 10 \mathrm{mg} / \mathrm{s}$.

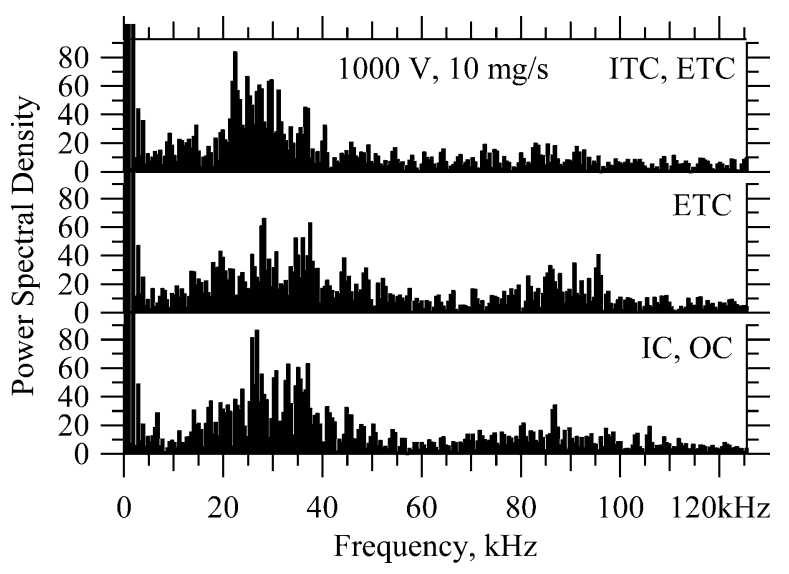

Fig. 20 Discharge current power spectra at $1000 \mathrm{~V}, 10 \mathrm{mg} / \mathrm{s}$.

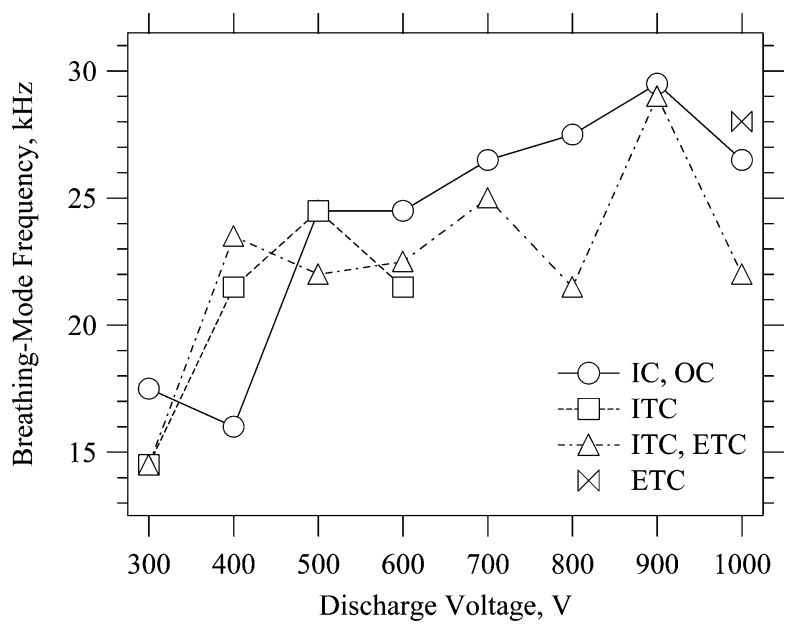

Fig. 21 Breathing-mode frequency vs discharge voltage at $10 \mathrm{mg} / \mathrm{s}$. much stronger peak when the trim coils were used. (This peak is usually associated with the breathing-mode ionization instability. ${ }^{35,53}$ ) Adding the external trim coil to the internal trim coil broadened the distribution, but there was still less broadening than when both trim coils were not used. In Fig. 18, the dependence of the standard deviation when the trim coils were energized was weak at $300 \mathrm{~V}$, indicating that more of the energy in the power spectrum was being concentrated into a narrower band of frequencies.

Figure 20 shows the power spectra at $1000 \mathrm{~V}$ for operation with only the external trim coil and then the combined influence of both trim coils. The external trim coil data at $1000 \mathrm{~V}$ showed broadening similar to when the external trim coil was added to the internal trim coil at $300 \mathrm{~V}$ (Fig. 19). A primary difference between 300 and $1000 \mathrm{~V}$ was the presence of a new oscillatory mode in the $80-90 \mathrm{kHz}$ frequency band. This mode was present at all voltages between 500 and $1000 \mathrm{~V}$, and in general the external trim coil excited the mode, whereas the internal trim coil dampened the mode.

Gascon et al. ${ }^{58}$ measured discharge current oscillations in a $1.35-\mathrm{kW}$ Hall thruster between discharge voltages of 100 and $600 \mathrm{~V}$. In that study, between 340 and $520 \mathrm{~V}$, high-frequency harmonics of the $20-25 \mathrm{kHz}$ breathing-mode frequency were measured between $45-55$ and $70-80 \mathrm{kHz}$, and at voltages of $540-600 \mathrm{~V}$, the breathingmode frequency suddenly decreased to $15 \mathrm{kHz}$, whereas the highfrequency harmonics were replaced with broadband noise between 10 and $60 \mathrm{kHz}$. In a companion paper to Ref. 58, using a numerical simulation, Barral et al. attributed the decrease in the breathingmode frequency to space-charge saturation of the wall sheaths due to the effects of intense secondary electron emission from the walls. ${ }^{59}$ Space-charge saturation also coincided with a sharp increase in the electron current and, therefore, a decrease in thruster efficiency.

It is significant that a decrease of the breathing-mode frequency similar to the findings in Refs. 58 and 59 was not observed in the NASA-173Mv2. As shown in Fig. 21, as the discharge voltage increased there was a gradual shift to higher breathing-mode frequencies, from $14.5 \mathrm{kHz}$ at $300 \mathrm{~V}$ to $22 \mathrm{kHz}$ at $1000 \mathrm{~V}$. Energizing the trim coils generally lowered the breathing-mode frequency for a fixed voltage. As shown in Fig. 18, a large increase in the standard deviation of the discharge current oscillations was measured between 300 and $400 \mathrm{~V}$, which persisted until $600 \mathrm{~V}$. Between 700 and $1000 \mathrm{~V}$, the standard deviation decreased again to another plateau. In general, energizing the trim coils decreased the magnitude of oscillations for a fixed voltage.

The increased oscillations between 400 and $600 \mathrm{~V}$ roughly coincided with the range of voltages where efficiency peaked in the NASA-173Mv1 and other Hall thrusters, that is, $500-800 \mathrm{~V}$ (Refs. 26-28 and 60). In those thrusters, it may be that efficiency decreased due to increased discharge current oscillations resulting from space-charge saturation of the wall sheaths. Above $600 \mathrm{~V}$ in the NASA-173Mv2, however, the continuous increase of the breathingmode frequency, the sharp decrease in oscillations, and the nearly ideal scaling of the thrust-to-total power ratio (at $10 \mathrm{mg} / \mathrm{s}$, Fig. 13) suggest that the magnetic field was effective at controlling oscillations and wall effects such that the electron current stabilized and the efficiency continued to increase. In part 2 of this paper, ${ }^{56}$ probe measurements taken between 300 and $900 \mathrm{~V}$ are reported that show the electron current was nearly constant with voltage, thus verifying this hypothesis.

\section{Conclusions}

The NASA-173M Hall thrusters were conceived to understand the design challenges and physical mechanisms determining the performance of high-specific impulse Hall thrusters. Although experiments with the NASA-173Mv1 established the validity of the plasma lens magnetic field design, the NASA-173Mv1 showed a maximum in the efficiency at an intermediate value of the specific impulse. With the NASA-173Mv2, the goal was to obtain a continuously increasing efficiency with increasing specific impulse. Experiments have confirmed that this goal was achieved.

The NASA-173Mv2 high-specific impulse experiments have demonstrated the influence of current density and magnetic field topography on performance, plume divergence, and discharge current 
oscillations. The maximum in the efficiency-specific impulse characteristic observed in other xenon Hall thrusters was eliminated. A performance mapping at voltages between 300 and $1000 \mathrm{~V}$ has shown for the first time that a minimum current density and optimum magnetic field exist at which efficiency will monotonically increase with specific impulse. Comparison of the NASA-173M thrusters showed that efficiency can be optimized for specific impulse by varying the plasma lens design. While enhancing performance overall, trim coils were not required to obtain a continuously increasing efficiency-specific impulse characteristic. This demonstrated that a traditional magnetic circuit can still be used if the magnetic field established by the standard inner coil and outer coil is properly designed. However, trim coils were shown to affect plume divergence and the frequency and magnitude of discharge current oscillations. This may prove to be the greatest utility of trim coils because controlling divergence and oscillations can benefit thruster lifetime. Finally, the breathing-mode frequency was shown to increase continuously with discharge voltage, in contrast to other thrusters, where a sudden decrease of the breathing-mode frequency was found to coincide with increasing electron current and decreasing efficiency. These results suggest that efficient, high-specific impulse operation was enabled through regulation of the electron current with the applied magnetic field. This hypothesis is verified in part 2 of this paper, ${ }^{56}$ where probe measurements are reported that show the electron current was nearly constant with voltage between 300 and $900 \mathrm{~V}$.

\section{Acknowledgments}

Support for this research through the former NASA Code R Energetics program is gratefully acknowledged. The authors would like to thank Christopher Griffiths for substantially improving the NASA-173M version 2 mechanical design from that of its predecessor and Kevin Blake for thruster assembly and installation support. We would also like to thank David Jacobson, David Manzella, and Peter Peterson for technical advice and insight.

\section{References}

${ }^{1}$ Kaufman, H. R., "Technology of Closed-Drift Thrusters," AIAA Journal, Vol. 23, No. 1, 1985, pp. 78-87.

${ }^{2}$ Kim, V., "Main Physical Features and Processes Determining the Performance of Stationary Plasma Thrusters," Journal of Propulsion and Power, Vol. 14, No. 5, 1998, pp. 736-743.

${ }^{3}$ Zhurin, V. V., Kaufman, H. R., and Robinson, R. S., "Physics of Closed Drift Thrusters," Plasma Sources Science and Technology, Vol. 8, No. 1, 1999, pp. R1-R20.

${ }^{4}$ Seikel, G. R., and Reshotko, E., "Hall Current Accelerator," Bulletin of the American Physical Society, Vol. 7, No. 2, 1962, pp. 414

${ }^{5}$ Lary, E. C., Meyerand, R. G., and Salz, F., "Ion Acceleration in a GyroDominated Neutral Plasma-Theory," Bulletin of the American Physical Society, Vol. 7, No. 2, 1962, pp. 441.

${ }^{6}$ Salz, F., Meyerand, R. G., and Lary, E. C., "Ion Acceleration in a GyroDominated Neutral Plasma-Experiment," Bulletin of the American Physical Society, Vol. 7, No. 2, 1962, pp. 441.

${ }^{7}$ Meyer, R. X., "Acceleration of Cesium Ions by Means of a Negative Space Charge Sheath," AIAA Paper 66-256, March 1966.

${ }^{8}$ Meyer, R. X., "A Space-Charge-Sheath Electric Thruster," AIAA Journal, Vol. 5, No. 11, 1967, pp. 2057-2059.

${ }^{9}$ Bober, A. S., and Maslennikov, N. A., "SPT in Russia-New Achievements," 24th International Electric Propulsion Conference, Paper IEPC-9506, Sept. 1995.

${ }^{10}$ Kim, V., "Electric Propulsion Activity in Russia," 27th International Electric Propulsion Conference, Paper IEPC-2001-005, Oct. 2001.

${ }^{11}$ Milligan, D., Gestal, D., Camino, O., Estublier, D., and Koppel, C., "SMART-1 Electric Propulsion Operations," AIAA Paper 2004-3436, July 2004.

${ }^{12}$ Spanjers, G. G., Birkan, M., and Lawrence, T. J., "The USAF Electric Propulsion Research Program,” AIAA Paper 2000-3146, July 2000.

${ }^{13}$ Oleson, S. R., and Sankovic, J. M., "Advanced Hall Electric Propulsion for Future in-Space Transportation,” NASA TM-210676, April 2001.

${ }^{14}$ Jankovsky, R. S., Jacobson, D. T., Rawlin, V. K., Mason, L. S., Mantenieks, M. A., Manzella, D. H., Hofer, R. R., and Peterson, P. Y., "NASA's Hall Thruster Program," NASA TM-2001-211215, Dec. 2001.

${ }^{15}$ Jankovsky, R. S., Jacobson, D. T., Pinero, L. R., Sarmiento, C. J., Manzella, D. H., Hofer, R. R., and Peterson, P., "NASA's Hall Thruster Program 2002," NASA TM-2002-211880, Sept. 2002.
${ }^{16}$ Jacobson, D. T., Manzella, D. H., Hofer, R. R., and Peterson, P. Y., "NASA's 2004 Hall Thruster Program," NASA TM-2004-213340, Oct. 2004.

${ }^{17}$ Gulczinksi, F. S., and Spores, R. A., "Analysis of Hall-Effect Thrusters and Ion Engines for Orbit Transfer Missions," AIAA Paper 96-2973, July 1996.

${ }^{18}$ Raitses, Y., Guelman, M., Ashkenazy, J., and Appelbaum, G., "Orbit Transfer with a Variable Thrust Hall Thruster Under Drag," Journal of Spacecraft and Rockets, Vol. 36, No. 6, 1998, pp. 875-881.

${ }^{19}$ Oleson, S. R., "Advanced Electric Propulsion for Space Solar Power Satellites," NASA TM-2000-210477, Nov. 2000.

${ }^{20}$ Oleson, S. R., "Advanced Electric Propulsion for RLV Launched Geosynchronous Spacecraft," 26th International Electric Propulsion Conference, Paper IEPC-99-185, Oct. 1999.

${ }^{21}$ Oleson, S. R., "Mission Advantages of Constant Power, Variable Isp Electrostatic Thrusters," NASA TM-2000-210477, Nov. 2000.

${ }^{22}$ Dudzinski, L. A., Hack, K. J., Gefert, L. P., Kerslake, T. W., and Hewston, A. W., "Design of a Solar Electric Propulsion Transfer Vehicle for a Non-Nuclear Human Mars Exploration Architecture," 26th International Electric Propulsion Conference, Paper IEPC-99-181, Oct. 1999.

${ }^{23}$ Fiehler, D., and Oleson, S., "A Comparison of Electric Propulsion Systems for Mars Exploration," NASA TM-2003-212593, Sept. 2003.

${ }^{24}$ Gefert, L. P., Hack, K. J., and Kerslake, T. W., "Options for the Human Exploration of Mars Using Solar Electric Propulsion," AIP Conf. No. 458, Space Technology and Applications International Forum (STAIF), Jan. 1999.

${ }^{25}$ Brophy, J. R., and Noca, M., "Electric Propulsion for Solar System Exploration," Journal of Propulsion and Power, Vol. 14, No. 5, 1998, pp. 700-707.

${ }^{26}$ Jacobson, D. T., Jankovsky, R. S., Rawlin, V. K., and Manzella, D. H., "High Voltage TAL Performance," NASA TM-2001-211147, Nov. 2001

${ }^{27}$ Manzella, D. H., Jacobson, D. T., and Jankovsky, R. S., "High Voltage SPT Performance," NASA TM-2001-211135, Nov. 2001

${ }^{28}$ Pote, B., and Tedrake, R., "Performance of a High Specific Impulse Hall Thruster," 27th International Electric Propulsion Conference, Paper IEPC-01-35, Oct. 2001

${ }^{29}$ Hofer, R. R., "Development and Characterization of High-Efficiency, High-Specific Impulse Xenon Hall Thrusters," Ph.D. Dissertation, Dept. of Aerospace Engineering, Univ. of Michigan, Ann Arbor, MI, Jan. 2004; also NASA/CR-2004-213099, June 2004.

${ }^{30}$ Hofer, R. R., Peterson, P. Y., Gallimore, A. D., and Jankovsky, R. S., "A High Specific Impulse Two-Stage Hall Thruster with Plasma Lens Focusing," 27th International Electric Propulsion Conference, Paper IEPC-01-36, Oct. 2001.

${ }^{31}$ Hofer, R. R., and Gallimore, A. D., "The Role of Magnetic Field Topography in Improving the Performance of High-Voltage Hall Thrusters," AIAA Paper 2002-4111, July 2002.

${ }^{32}$ Belikov, M. B., Gorshkov, O. A., Rizakhanov, R. N., Shagayda, A. A., and Khartov, S. A., "Hall-Type Low- and Mean-Power Thrusters Output Parameters," AIAA Paper 99-2571, June 1999.

${ }^{33}$ Garrigues, L., Hagelaar, G. J. M., Bareilles, J., Boniface, C., and Boeuf, J. P., "Model Study of the Influence of the Magnetic Field Configuration on the Performance and Lifetime of a Hall Thruster," Physics of Plasmas, Vol. 10, No. 12, 2003, pp. 4886-4892.

${ }^{34}$ Morosov, A. I., "Focusing of Cold Quasineutral Beams in Electromagnetic Fields," Soviet Physics-Doklady, Vol. 10, No. 8, 1966, pp. $775-777$.

${ }^{35}$ Fife, J. M., "Hybrid-PIC Modeling and Electrostatic Probe Survey of Hall Thrusters," Ph.D. Dissertation, Dept. of Aeronautics and Astronautics, Massachusetts Inst. of Technology, Cambridge, MA, Sept. 1998.

${ }^{36}$ Hagelaar, G. J. M., Bareilles, J., Garrigues, L., and Boeuf, J. P., "TwoDimensional Model of a Stationary Plasma Thruster," Journal of Applied Physics, Vol. 91, No. 9, 2002, pp. 5592-5598.

${ }^{37}$ Morosov, A. I., Esipchuk, Y. V., Tilinin, G. N., Trofimov, A. V., Sharov, Y. A., and Shchepkin, G. Y., "Plasma Accelerator with Closed Electron Drift and Extended Acceleration Zone," Soviet Physics Technical Physics, Vol. 17, No. 1, 1972, pp. 38-45.

${ }^{38}$ Morosov, A. I., Esipchuk, Y. V., Kapulkin, A. M., Nevrovskii, V. A., and Smirnov, V. A., "Effect of the Magnetic Field on a Closed-ElectronDrift Accelerator," Soviet Physics Technical Physics, Vol. 17, No. 3, 1972, pp. 482-487.

${ }^{39}$ Kim, V., Grdlichko, D., Kozlov, V., Lazourenko, A., Popov, G., and Skrylnikov, A., "Local Plasma Parameter Measurements by Nearwall Probes inside the SPT Accelerating Channel under Thruster Operation with Kr," AIAA Paper 2002-4108, July 2002.

${ }^{40}$ Kim, V., Popov, G., Kozlov, V., Skrylnikov, A., and Grdlichko, D., "Investigation of SPT Performance and Particularities of Its Operation with $\mathrm{Kr}$ and $\mathrm{Kr} / \mathrm{Xe}$ Mixtures," 27th International Electric Propulsion Conf., Paper IEPC-01-065, Oct. 2001. 
${ }^{41}$ Kim, V., Grdlichko, D., Kozlov, V., and Lazurenko, A., "SPT115 Development and Characterization," AIAA Paper 99-2568, June 1999.

${ }^{42}$ King, D. Q., and de Grys, K. H., "Multi-Mode Hall Thruster Development," AIAA Paper 2001-3778, July 2001.

${ }^{43}$ Bugeat, J. P., and Koppel, C., "Development of a Second Generation of SPT," 24th International Electric Propulsion Conf., Paper IEPC-95-35, Sept. 1995.

${ }^{44}$ Day, M., Kim, V., Kozlov, V., Lazurenko, A., Popov, G., and Skrylnikov, A., "Investigation of the Possibility to Reduce SPT Plume Divergence by Optimization of the Magnetic Field Topology in the Accelerating Channel," 25th International Electric Propulsion Conf., Paper IEPC-97-154, Aug. 1997.

${ }^{45}$ Mason, L. S., Jankovsky, R. S., and Manzella, D. H., "1000 Hours of Testing on a 10 Kilowatt Hall Effect Thruster," AIAA Paper 2001-3773, July 2001.

${ }^{46}$ Jacobson, D. T., "High Voltage TAL Erosion Characterization," NASA TM-2003-211879, Feb. 2003.

47 Jankovsky, R. S., McLean, C., and McVey, J., "Preliminary Evaluation of a 10 kW Hall Thruster,” NASA TM-1999-209075, April 1999.

${ }^{48}$ Hofer, R. R., Peterson, P. Y., and Gallimore, A. D., "Characterizing Vacuum Facility Backpressure Effects on the Performance of a Hall Thruster," 27th International Electric Propulsion Conf., Paper IEPC-01-45, Oct. 2001.

${ }^{49}$ Walker, M. L. R., Hofer, R. R., and Gallimore, A. D., "Ion Collection in Hall Thruster Plumes," Journal of Propulsion and Power, Vol. 22, No. 1, 2006, pp. 205-209.

${ }^{50}$ Manzella, D. H., and Sankovic, J. M., "Hall Thruster Ion Beam Characterization," NASA TM-107034, Aug. 1995.
${ }^{51}$ Boyd, I. D., "Review of Hall Thruster Plume Modeling," Journal of Spacecraft and Rockets, Vol. 38, No. 3, 2001, pp. 381-387.

${ }^{52}$ McVey, J. B., Britt, E. J., Engelman, S. F., Gulczinski, F. S., Beiting, E. D., and Pollard, J. E., "Characteristics of the T-220HT Hall-Effect Thruster," AIAA Paper 2003-5158, July 2003.

${ }^{53}$ Choueiri, E. Y., "Plasma Oscillations in Hall Thrusters," Physics of Plasmas, Vol. 8, No. 4, 2001, pp. 1411-1426.

${ }^{54}$ Hofer, R. R., and Gallimore, A. D., "Recent Results from Internal and Very-Near-Field Plasma Diagnostics of a High Specific Impulse Hall Thruster," NASA CR-2003-212604, Dec. 2003.

${ }^{55}$ Hofer, R. R., Haas, J. M., and Gallimore, A. D., "Ion Voltage Diagnostics in the Far-Field Plume of a High-Specific Impulse Hall Thruster,' NASA CR-2003-212895, Dec. 2003.

${ }^{56}$ Hofer, R. R., and Gallimore, A. D., "High-Specific Impulse Hall Thrusters, Part 2: Efficiency Analysis," Journal of Propulsion and Power (to be published).

${ }^{57}$ Ashkenazy, J., Raitses, Y., and Appelbaum, G., "Parametric Studies of the Hall Current Plasma Thruster,' Physics of Plasmas, Vol. 5, No. 5, 1998, pp. 2055-2063.

${ }^{58}$ Gascon, N., Dudeck, M., and Barral, S., "Wall Material Effects in Stationary Plasma Thrusters I: Parametric Studies of an SPT-100," Physics of Plasmas, Vol. 10, No. 10, 2003, pp. 4123-4136.

${ }^{59}$ Barral, S., Makowski, K., Peradzynski, Z., Gascon, N., and Dudeck, M., "Wall Material Effects in Stationary Plasma Thrusters II: Near-Wall and In-Wall Conductivity," Physics of Plasmas, Vol. 10, No. 10, 2003, pp. 4137-4152.

${ }^{60}$ Azziz, Y., Warner, N. Z., Martinez-Sanchez, M., and Szabo, J. J., "High Voltage Plume Measurements and Internal Probing of the BHT-1000 Hall Thruster," AIAA Paper 2004-4097, July 2004. 